\title{
Synthesis and Characterization of Poly(E-caprolactone-b-Styrene) Block Copolymer by Ring- Opening Polymerization and Reversible Addition-Fragmentation Chain Transfer Polymerization
}

\section{Bedrettin SAVASุ ${ }^{1 *}$, Temel ÖZTÜRK ${ }^{2}$}

\begin{abstract}
The synthesis of the block copolymer was carried out using the RAFT polymerization technique and the ring-opening polymerization (ROP) technique using a novel two functional initiator (RAFT-ROP agent). For this purpose, RAFT-ROP agent was obtained using 5-bromo-2hydroxybenzaldehyde and potassium salt of ethyl xanthogenate. RAFT-macro agent was synthesized by ROP of $\varepsilon$-caprolactone (CL) with RAFT-ROP agent. Then, poly(e-caprolactone-b-styrene) block copolymer was synthesized using RAFT polymerization in the presence of RAFT-macro agent using styrene. The products were characterized using GPC, FT-IR and 1H-NMR analyses. Decomposition temperatures of the block copolymer were monitored by TGA method. Spectroscopic and thermal analyses revealed that the reactions were successfully carried out.
\end{abstract}

Keywords: Novel Two Functional Initiator; RAFT-Macro Agent; Block Copolymer; RAFT Polymerization; Ring-Opening Polymerization (ROP).

${ }^{1}$ Bedrettin SAVAŞ (Orcid ID: 0000-0002-6620-5493, Kafkas University, Kars Vocational School, Kars, Turkey

${ }^{2}$ Temel ÖZTÜRK (Orcid ID: 0000-0002-7856-9809), Giresun University, Faculty of Arts and Sciences, Department of Chemistry, Giresun, Turkey

*Sorumlu Yazar/Corresponding Author: Bedrettin SAVAŞ. e-mail: bdrttn.svs.36@gmail.com

Geliș tarihi / Received: 10/02/2020

Kabul tarihi / Accepted: 26/03/2020 


\section{INTRODUCTION}

Recently, complex-structured macromolecules, in which the polymer chain end functionality and the block and graft chain fragment are arranged, are highly synthesized starting from controlled polymerization processes (Nomura and Abdellatif 2010; Cai, Li et al., 2012; Chang and Dong 2013). Multipurpose polymer chains are combined in the desired polymer architecture. Block copolymers have attracted great attention in many areas. These areas are surfactants, adhesive, thermoplastic elastomers, dispersants, etc. (Matzner, Noshay et al., 1977; Price and Goodman 1982). RAFT polymerization technique is the latest development of the controlled free-radical polymerization method. And this method is a powerful technique for macromolecular synthesis (Chiefari, Chong et al., 1998; Patton, Mullings, et al., 2005; Yang, Chai et al., 2011; Öztürk, Atalar et al., 2013; Robin, Wilson et al., 2013; Schmidt and Barner-Kowollik, 2013; Bağlan et al., 2018). The usefulness of the method has been demonstrated by its compatibility with many various monomers and reaction conditions (Xie, Dang et al., 2008). Reversible chain transfer contains homolytic replacement, addition breakup, or another transfer techniques (Kartal et al., 2014). Graft and block copolymers are used in both theoretical research and technological applications (Ruzette and Leibler 2005; Ozturk, Yilmaz et al., 2008; Öztürk, Göktaş et al., 2010; Noshay and McGrath 2013; Göktaş, Öztürk et al., 2014; Öztürk, Göktaş et al., 2014; Çakmak et al., 2017). Lactones show special properties such as biocompatibility, good mechanical properties, biodegradability, and no toxicity. Therefore, ring-opening polymerization (ROP) of lactones is of great interest (Gross, Kumar et al., 2001; Kobayashi, Uyama et al., 2001; Cretu, Gattin et al., 2004; Öztürk et al., 2019).

This study shows the synthesis of poly(c-caprolactone-b-styrene) [poly(CL-b-St)] block copolymer by using ROP and RAFT polymerization. For this purpose, a novel two functional initiator (RAFT-ROP agent) was obtained using 5-bromo-2-hydroxybenzaldehyde and potassium salt of ethyl xanthogenate. Then, RAFT-macro agent was synthesized by ROP of $\varepsilon$-caprolactone (CL) with RAFTROP agent. RAFT-macro agent and styrene (St) were used to obtain poly(CL-b-St) block copolymer by RAFT polymerization. Characterization of block copolymer was done in detail.

\section{MATERIALS AND METHODS}

\section{Materials}

5-bromo-2-hydroxybenzaldehyde, 2,2'-azobis(2-methylpropionitrile) (AIBN), potassium ethyl xanthogenate, St, and CL were supplied by Merck. Methanol, N,N-dimethylformamide (DMF), tetrahydrofuran (THF), toluene and stannous octoate $\left[\mathrm{Sn}(\mathrm{Oct})_{2}\right]$ were received from Sigma-Aldrich. $\mathrm{Sn}(\mathrm{Oct})_{2}$ was used as a catalyst for ROP. The alumina column was used to send away inhibitors from St. The other chemicals were used without further purifications.

\section{Instrumentation}

The number of molecular weight $(\mathrm{Mn})$, molecular weight $(\mathrm{Mw})$ and dispersity values were evaluated with the GPC-Shimadzu (RID-10A GPC) / HPLC device with THF mobile phase of $40{ }^{\circ} \mathrm{C}$. ${ }^{1} \mathrm{H}-\mathrm{NMR}$ peaks were found on Bruker UltraShield Plus instrument using NMR 400 spectrometer. FTIR spectra were recorded by (IR 6600 FT-IR) / Jasco FT brand device. TGA values were obtained by (Exstar 6000) Seiko II model device. The product was heated from $30{ }^{\circ} \mathrm{C}$ to $800{ }^{\circ} \mathrm{C}$ under $\mathrm{N}_{2}$, changing at $10{ }^{\circ} \mathrm{C}$ per minute. 


\section{Synthesis of novel two functional initiator (RAFT-ROP agent)}

A $250 \mathrm{~mL}$ flask was mixed with $30 \mathrm{~mL}$ of THF, $1.004 \mathrm{~g}$ of 5-bromo-2-hydroxybenzaldehyde, $1.612 \mathrm{~g}$ of potassium ethyl xanthogenate, respectively. The flask containing the mixture was placed on a magnetic stirrer in an oil bath at $30^{\circ} \mathrm{C}$. After 72 hours, the content was filtered to remove the unreacted salts. The solvent partially removed. The residue was precipitated in cold diethyl ether and petroleum ether $[1(\mathrm{v}) / 1(\mathrm{v})]$. The mixture was kept in a refrigerator overnight. After decantation, RAFT-ROP agent was dried in a vacuum oven at room temperature for 48 hours. RAFT-ROP agent yield was determined gravimetrically.

\section{Synthesis of RAFT-macro agent by ROP}

$0.192 \mathrm{~g}$ of $\mathrm{Sn}(\mathrm{Oct})_{2}, 0.320 \mathrm{~g}$ of RAFT-ROP agent, $15.093 \mathrm{~g}$ of CL, and $10 \mathrm{~mL}$ of DMF were placed in a $250 \mathrm{~mL}$ glass flask, respectively. Argon gas was passed through for 5 minutes to obtain inert medium. After the glass vial was capped, the flask was stirred in an oil bath for 72 hours at $110^{\circ} \mathrm{C}$. The mixture was cooled to room temperature and then poured into excess methanol. After decantation, RAFT-macro agent was dried in a vacuum oven at room temperature for 24 hours. The product yield was defined gravimetrically.

\section{Synthesis of poly(CL-b-St) block copolymer by RAFT polymerization}

$0.109 \mathrm{~g}$ of RAFT-macro agent, $2.010 \mathrm{~g}$ of St, $0.001 \mathrm{~g}$ of AIBN, and $2 \mathrm{~mL}$ of toluene were placed in a $250 \mathrm{~mL}$ glass flask, respectively. Argon gas was passed through for 5 minutes to obtain inert medium. The flask was placed on a magnetic stirrer in an oil bath at $90^{\circ} \mathrm{C}$. After 24 hours, poly (CL-bSt) block copolymer was poured into excess methanol. The precipitated copolymer was dried in a vacuum oven at room temperature for 48 hours. The copolymer yield was defined gravimetrically.

\section{RESULTS AND DISCUSSION}

\section{Synthesis of RAFT-ROP agent}

RAFT-ROP agent was obtained by reaction of 5-bromo-2-hydroxybenzaldehyde and potassium ethyl xanthogenate. The yield was obtained with a $42.99 \mathrm{wt} \%$. The chemical synthesis mechanism of RAFT-ROP agent was shown in Scheme 1.

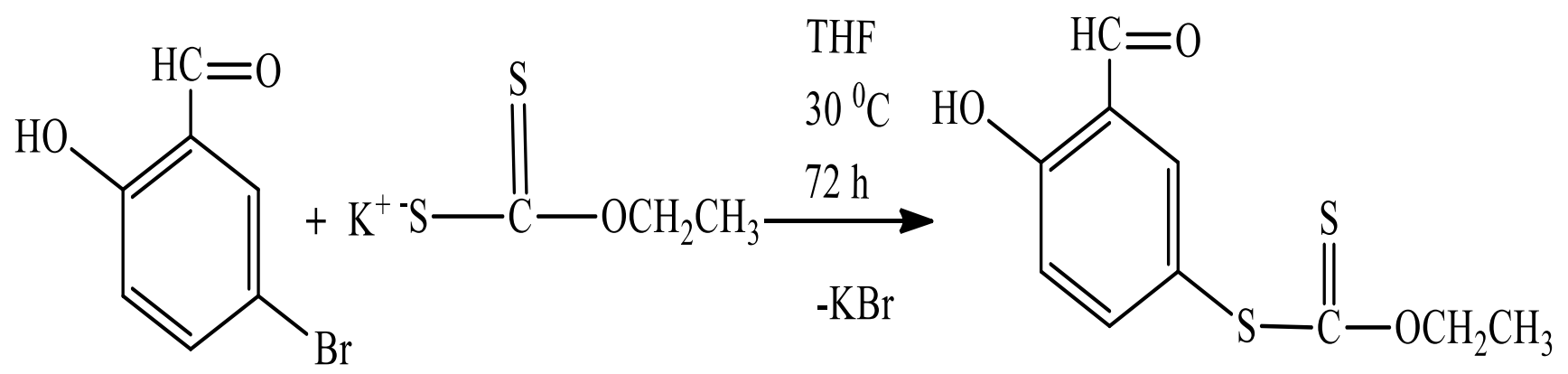

Scheme 1. The mechanism of RAFT-ROP agent.

\section{Synthesis of RAFT-macro agent}

RAFT-macro agent was synthesized by reaction of RAFT-ROP agent and CL via ROP. Scheme 2 (first line and second line) shows the synthesis route for the RAFT-macro agent. The yield of RAFT-

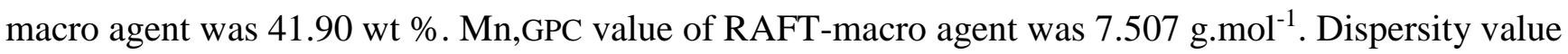


of RAFT-macro agent was 1.20. The ${ }^{1} \mathrm{H}-\mathrm{NMR}$ spectrum of RAFT-macro agent in Figure 1(a) displayed peaks at $1.2 \mathrm{ppm}$ for $-\mathrm{CH}_{3}$ of ethyl xanthogenate unit, $1.6 \mathrm{ppm}$ for $-\mathrm{CH}_{2}$ of PCL unit, $2.3 \mathrm{ppm}$ for $-\mathrm{CH}_{2}$ linked carbonyl group of PCL unit, $3.4 \mathrm{ppm}-\mathrm{OH}$ of PCL unit, $3.6 \mathrm{ppm}$ for $-\mathrm{OCH}_{2}$ of ethyl xanthogenate unit, $4.0 \mathrm{ppm}$ for $-\mathrm{OCH}_{2}$ of PCL unit, $7.8 \mathrm{ppm}$ and $7.9 \mathrm{ppm}$ for aromatic $-\mathrm{CH}, 8.2 \mathrm{ppm}$ for $-\mathrm{HC}=\mathrm{O}$. The FT-IR spectrum of RAFT-macro agent in Figure 2(a) indicated signals at 2944 and $2900 \mathrm{~cm}^{-1}$ for aliphatic $-\mathrm{CH}_{3}$ and $-\mathrm{CH}_{2}, 1720 \mathrm{~cm}^{-1}$ for $\mathrm{C}=\mathrm{O}, 1174 \mathrm{~cm}^{-1}$ for $-\mathrm{OC}, 1107 \mathrm{~cm}^{-1}$ for $-\mathrm{SC}$.<smiles>CCOC(=S)Sc1ccc(O)c(C=O)c1</smiles>

$$
\begin{aligned}
& \mathrm{CL} \\
& \mathrm{DMF} \\
& \mathrm{Sn}(\mathrm{Oct})_{2} \\
& 110{ }^{0} \mathrm{C}
\end{aligned}
$$

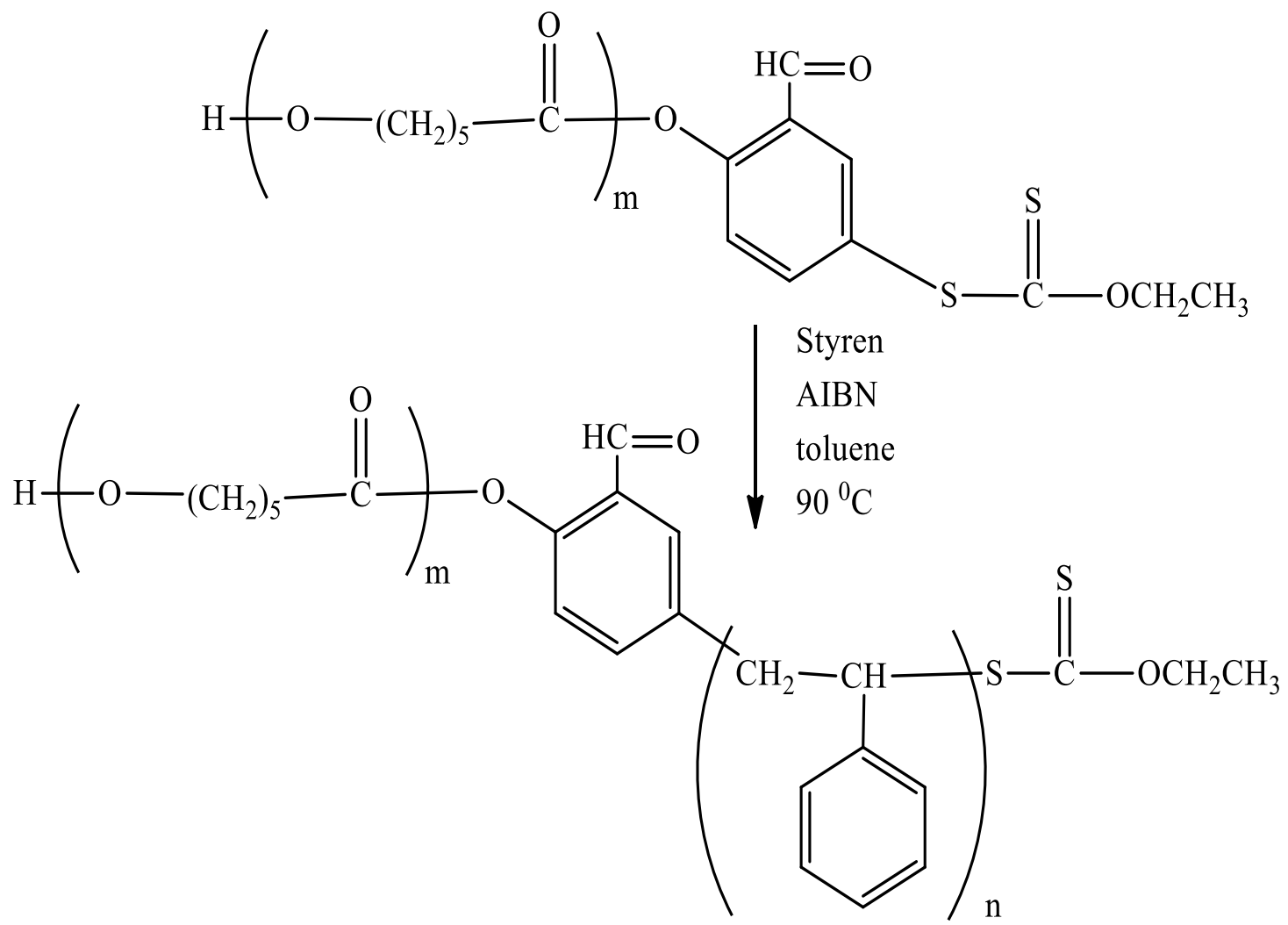

Scheme 2. Reaction outlines for syntheses of RAFT-macro agent and poly(CL-b-St) block copolymer. 


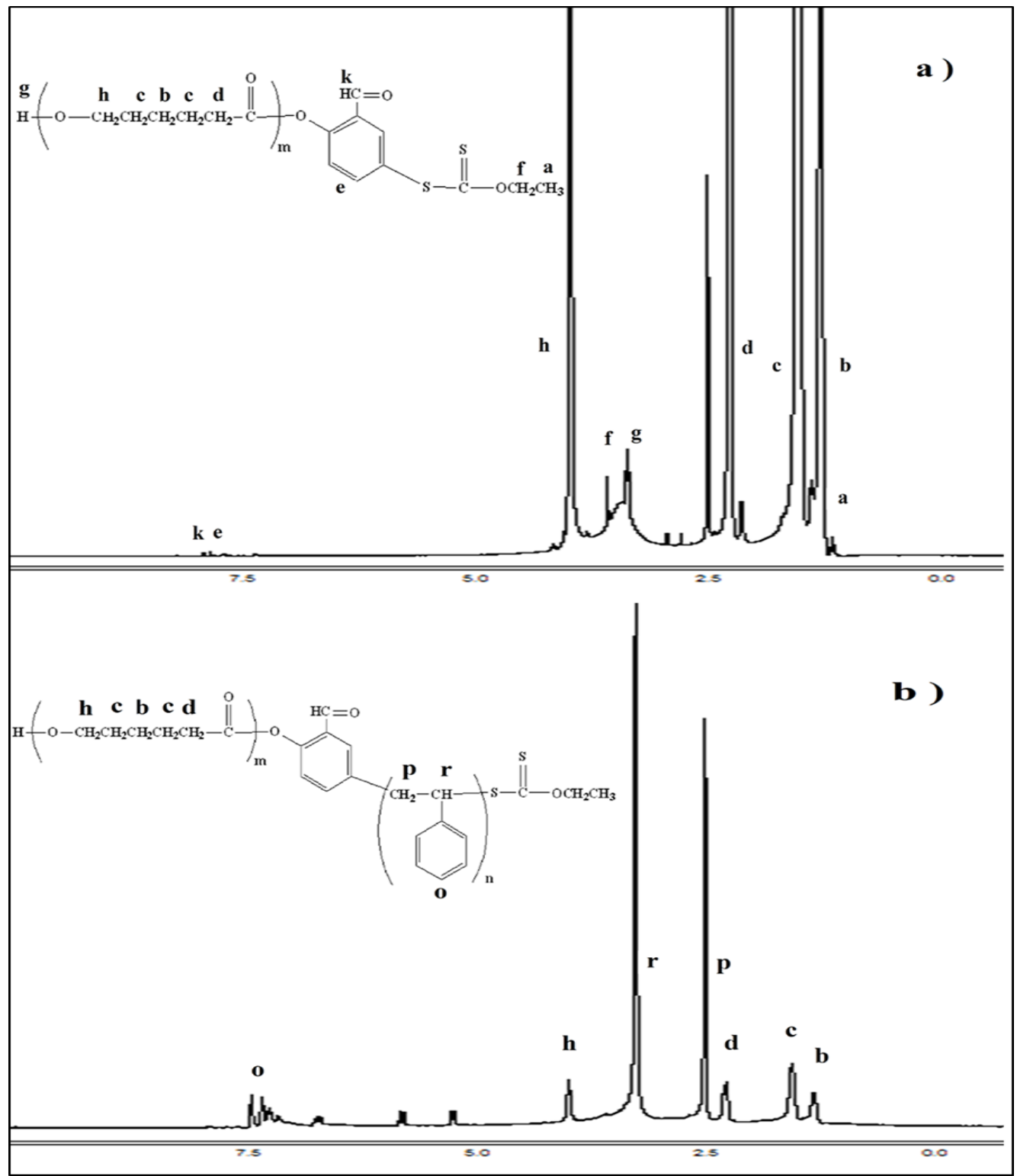

Figure 1. ${ }^{1} \mathrm{H}-\mathrm{NMR}$ spectra of (a) RAFT-macro agent; (b) poly(CL-b-St) block copolymer.

\section{Synthesis of poly(CL-b-St) block copolymer}

Poly(CL-b-St) block copolymer was synthesized by RAFT polymerization of RAFT-macro agent and St at $90{ }^{\circ} \mathrm{C}$. Scheme 2 (second line and third line) indicates the synthesis route for the block copolymer. The block copolymer yield was $52 \mathrm{wt} \%$. Mn,GPC of poly(CL-b-St) block copolymer was $66,683 \mathrm{~g} \cdot \mathrm{mol}^{-1}$. Dispersity value of the block copolymer was 2.70 . Increases in the molecular weight of poly(CL-b-St) block copolymer as compared with the molecular weight of RAFT-macro agent was proved the production of the block copolymer. The ${ }^{1} \mathrm{H}-\mathrm{NMR}$ spectrum of the copolymer in Figure 1(b) displayed peaks at $1.6 \mathrm{ppm}$ for $-\mathrm{CH}_{2}$ of PCL unit, $2.3 \mathrm{ppm}$ for $-\mathrm{CH}_{2}$ linked carbonyl group of PCL unit, $2.5 \mathrm{ppm}$ for $-\mathrm{CH}_{2}$ of PS unit, $3.3 \mathrm{ppm}$ for $-\mathrm{CH}$ of PS unit, $4.0 \mathrm{ppm}$ for $-\mathrm{OCH}_{2}$ of PCL unit, $7.3 \mathrm{ppm}$ and $7.5 \mathrm{ppm}$ for aromatic -CH of PS unit. The FT-IR spectrum of the copolymer in Figure 2(b) indicated signals at $3025 \mathrm{~cm}^{-1}$ for aromatic $-\mathrm{CH}, 2920$ and $2860 \mathrm{~cm}^{-1}$ for aliphatic $-\mathrm{CH}_{3},-\mathrm{CH}_{2}$ and $-\mathrm{CH}, 1720 \mathrm{~cm}^{-}$ ${ }^{1}$ for $\mathrm{C}=\mathrm{O}, 1490 \mathrm{~cm}^{-1}$ for aromatic $-\mathrm{C}=\mathrm{C}, 1190 \mathrm{~cm}^{-1}$ for $-\mathrm{OC}, 1070 \mathrm{~cm}^{-1}$ for $-\mathrm{SC}$. 


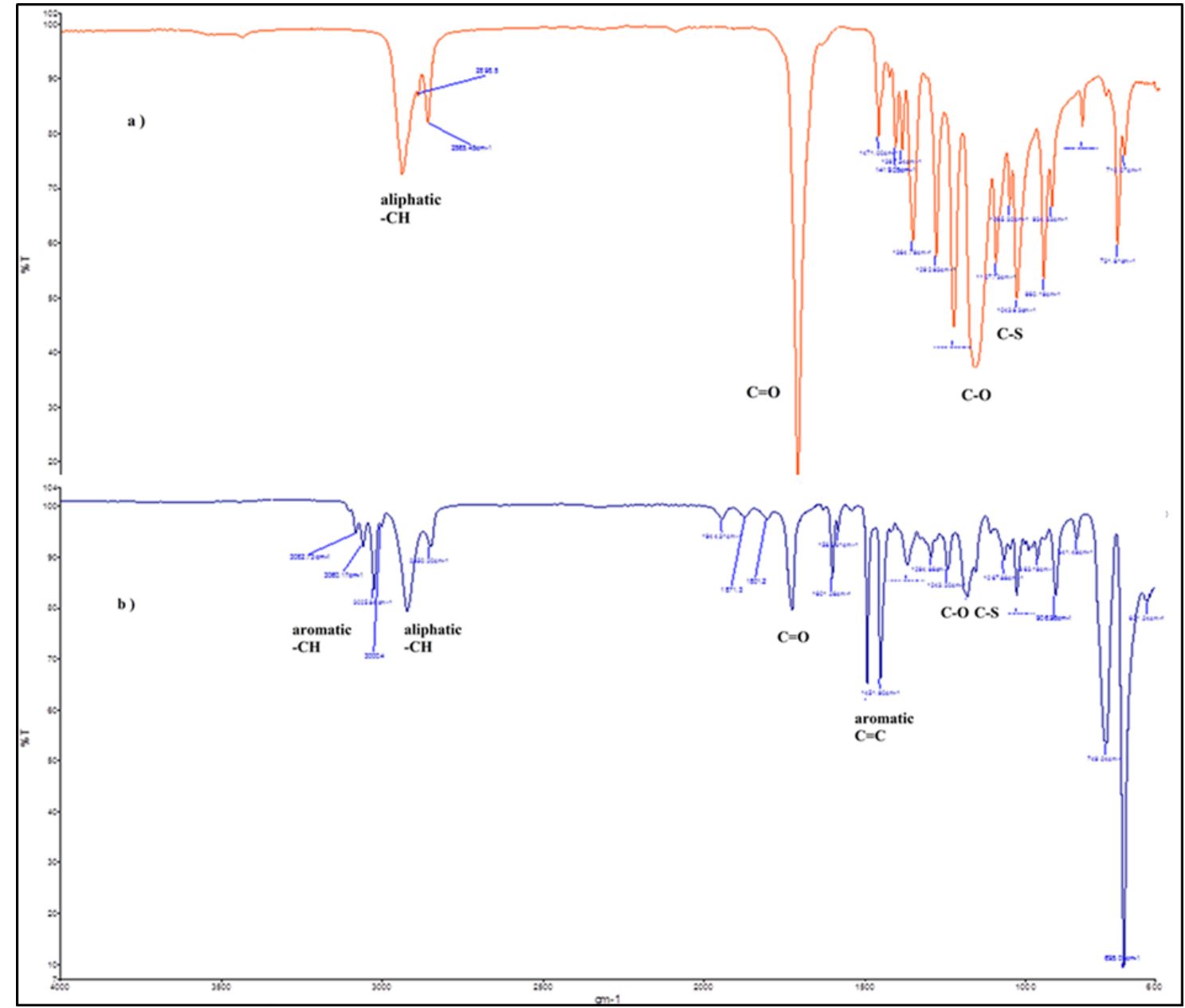

Figure 2. FT-IR spectra of (a) RAFT-macro agent; (b) poly(CL-b-St) block copolymer.

Thermal properties of poly(CL-b-St) block copolymer were shown by TGA method. When the TGA curves of the poly (CL-b-St) block copolymer are examined, it is seen that the degradation starts from $300{ }^{\circ} \mathrm{C}$ to $450{ }^{\circ} \mathrm{C}$ and the maximum degradation is at $418{ }^{\circ} \mathrm{C}$ as shown Figure 4 . In the poly(CLb-St) block copolymer, the PCL and PS units do not have separate decomposition temperature (Td) values. A single Td value of the block copolymer can show a high level of compatibility of the block copolymer in the amorphous regions of the PCL and PS.

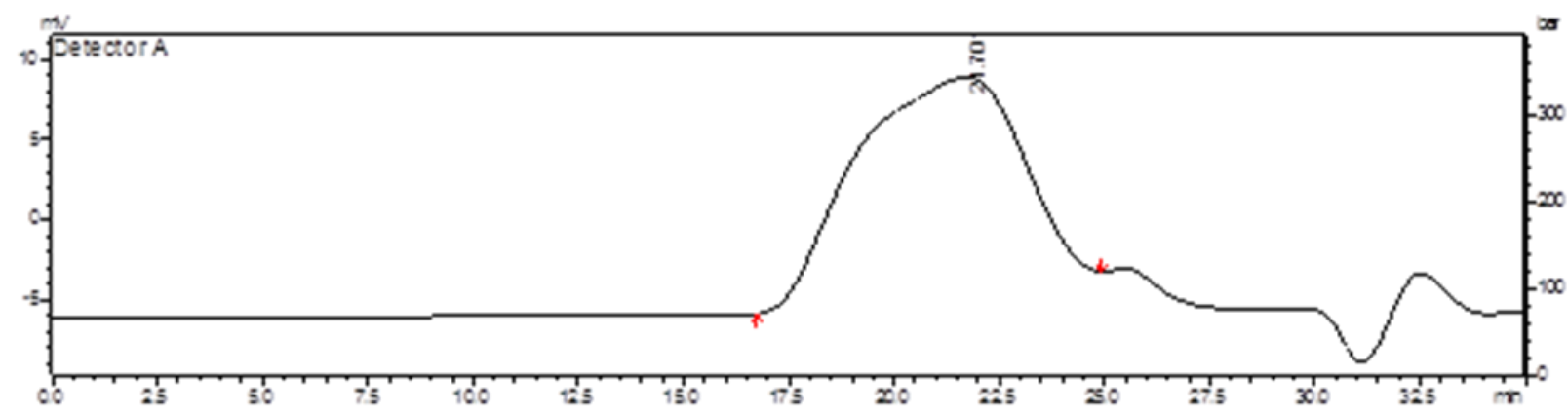

Figure 3. GPC curve of poly(CL-b-St) block copolymer. 


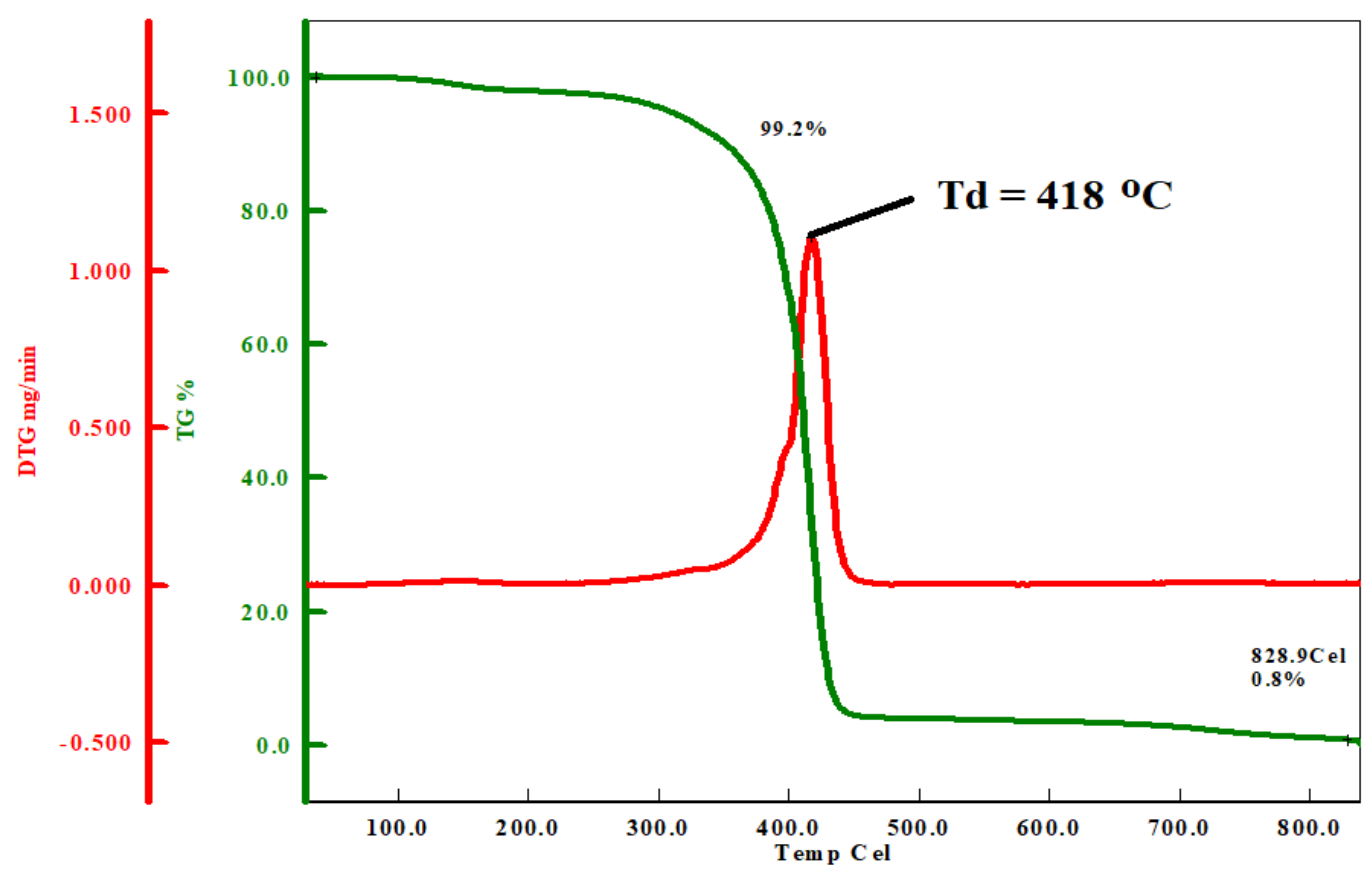

Figure 4. TGA curve of poly(CL-b-St) block copolymer.

\section{CONCLUSIONS}

Synthesis of poly(CL-b-St) block copolymer was performed with RAFT and ROP. The block copolymer was obtained with relatively high molecular weight. The method is simple and effective for synthesis of block copolymer. This study showed that the materials obtained with the synergistic combination of PCL and PS can be used in areas with wide technological application potential.

\section{REFERENCES}

Bağlan M, Yildiko, U, Cakmak, I, Tekeş, AT. (2018). Synthesis of PMMA-b-PEG-b-PMMA by controlled Polymerization Using Macro-RAFT Agents. Journal of the Institute of Science and Technology 8(3): 243254.

Cai T, Li M, Neoh KG, Kang ET. 2012. Preparation of stimuli responsive polycaprolactone membranes of controllable porous morphology via combined atom transfer radical polymerization, ring-opening polymerization and thiol-yne click chemistry. Journal of Materials Chemistry 22(32): 16248-16258.

Chang X, Dong CM. 2013. Synthesis of hyperbranched polypeptide and PEO block copolymer by consecutive thiol-yne chemistry. Biomacromolecules 14(9): 3329-3337.

Chiefari J, Chong Y, Ercole F, Krstina J, Jeffery J, Le TP, Mayadunne RT, Meijs GF, Moad CL, Moad G. 1998. Living free-radical polymerization by reversible addition-fragmentation chain transfer: the RAFT process. Macromolecules 31(16): 5559-5562.

Cretu A, Gattin R, Brachais L, Barbier-Baudry D. 2004. Synthesis and degradation of poly(2-hydroxyethyl methacrylate)-graft-poly(e-caprolactone) copolymers. Polymer Degradation and Stability 83(3): 399-404.

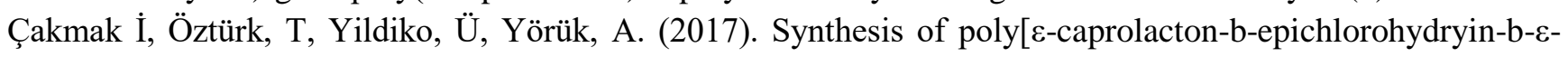
caprolactone]-g-poly(styrene) Block-Graft Copolymers via Cationic Ring Opening and Atom Transfer Radical Polymerization Transformations. Journal of the Institute of Science and Technology 7(3): 161-169.

Göktaş M, Öztürk T, Atalar MN, Tekeş AT, Hazer B. 2014. One-step synthesis of triblock copolymers via simultaneous reversible-addition fragmentation chain transfer (RAFT) and ring-opening polymerization using a novel difunctional macro-RAFT agent based on polyethylene glycol. Journal of Macromolecular Science, Part A 51(11): 854-863. 
Gross RA, Kumar A, Kalra B. 2001. Polymer synthesis by in vitro enzyme catalysis. Chemical Reviews 101(7): 2097-2124.

Kartal B, Yildiko, U, Ozturk, S, Ata, AC, Cakmak, I. (2014). Study of Solution Polymerization of Styrene in the Presence of Poly(ethylene glycol)-RAFT Agents Possessing Benzoyl Xanthate Derivatives. Journal of Macromolecular Science, Part A 51(12): 990-998.

Kobayashi S, Uyama H, Kimura S. 2001. Enzymatic Polymerization. Chemical Reviews 101(12): 3793-3818.

Matzner M, Noshay A, McGrath J. 1977. Effect of Hard Segment Chemical Structure on the Processibility of Organo-Siloxane Block Copolymers. Transactions of the Society of Rheology 21(2): 273-290.

Nomura K, Abdellatif MM. 2010. Precise synthesis of polymers containing functional end groups by living ringopening metathesis polymerization (ROMP): Efficient tools for synthesis of block/graft copolymers. Polymer 51(9): 1861-1881.

Noshay A, McGrath JE. 2013. Block Copolymers: Overview and Critical Survey, Elsevier.

Özturk, T, Yilmaz SS, Hazer B. 2008. Synthesis of a new macroperoxy initiator with methyl methacrylate and tbutyl peroxy ester by atom transfer radical polymerization and copolymerization with conventional vinyl monomers. Journal of Macromolecular Science, Part A 45(10): 811-820.

Öztürk, T, Atalar MN, Göktaş M, Hazer B. 2013. One-step synthesis of block-graft copolymers via simultaneous reversible-addition fragmentation chain transfer and ring-opening polymerization using a novel macroinitiator. Journal of Polymer Science Part A: Polymer Chemistry 51(12): 2651-2659.

Öztürk T, Göktaş M, Hazer B, 2010. One-step synthesis of triarm block copolymers via simultaneous reversible-addition fragmentation chain transfer and ring-opening polymerization. Journal of Applied Polymer

Science 117(3): 1638-1645.

Öztürk T, Göktaş M, Savaş B, Işıklar M, Atalar MN, Hazer B. 2014. Synthesis and characterization of poly(vinyl chloride-graft-2-vinylpyridine) graft copolymers using a novel macroinitiator by reversible additionfragmentation chain transfer polymerization. e-Polymers 14(1): 27-34.

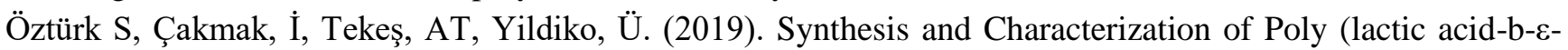
caprolactone) Block Copolymers. Journal of the Institute of Science and Technology 9(2): 1035-1045.

Patton DL, Mullings M, Fulghum T, Advincula RC. 2005. A facile synthesis route to thiol-functionalized $\alpha, \omega-$ telechelic polymers via reversible addition fragmentation chain transfer polymerization. Macromolecules 38(20): 8597-8602.

Price C, Goodman I. 1982. Developments in Block Copolymers. Elsevier Applied Science, London.

Robin MP, Wilson P, Mabire AB, Kiviaho JK, Raymond JE, Haddleton DM, Reilly RKO. 2013. Conjugationinduced fluorescent labeling of proteins and polymers using dithiomaleimides. Journal of the American Chemical Society 135(8): 2875-2878.

Ruzette AV, Leibler L. 2005. Block Copolymers in Tomorrow's Plastics. Nature Materials 4(1): 19-31.

Schmidt BVKJ, Barner-Kowollik C. 2013. Polymer Chemistry: Macromolecules Made to Order. Nature Chemistry 5(12): 990-992.

Xie M, Dang J, Han H, Wang W, Liu J, He X, Zhang Y. 2008. Well-defined brush copolymers with high grafting density of amphiphilic side chains by combination of ROP, ROMP, and ATRP. Macromolecules 41(23): 9004-9010.

Yang G, Chai Y, Zhang P. 2011. Synthesis of PMMA-b-PS by RAFT Mini-emulsion Polymerization and their Self-Assembly. Journal of Polymer Materials 28(4): 517-523. 